\title{
Bruk av stråleterapi i Helse Sør-øst
}

\begin{abstract}
Samandrag
Bakgrunn. Gjennom satsinga i Nasjonal kreftplan fekk ein på plass dei utstyrsmessige føresetnadene for å dekkje dei medisinske behova for strålebehandling av kreft. Målet med denne studien er å vise utviklinga i stråleterapibruken i Helse Sør-Øst, knytt opp mot målsettingane i kreftplanen.
\end{abstract}

Materiale og metode. Materialet omfattar dei 86000 utførde strålebehandlingsseriane for pasientar i noverande Helse Sør-Øst i perioden 1985-2008. Data er henta ut frå eksisterande pasientregister, der også kreftdiagnose og demografiske data er med. Talet på behandlingsseriar er relatert til kreftinsidensen for kvart fylke og for heile regionen.

Resultat. I andre halvdel av 1980-åra vart berre $50 \%$ av behova for stråleterapi dekte, med fylkesvise variasjonar frå $30 \%$ til $60 \%$. I 2007 vart nær $80 \%$ av behova dekte, framleis med betydeleg fylkesvis variasjon (67-91\%). Jamført med dei medisinske behova mangla det 10000 strålebehandlingsseriar i regionen for femårsperioden 2003-07.

Tolking. Det dokumenterte underforbruket og dei geografiske skilnadene i stråleterapibruken er uakseptable. Etablering av onkologisk kompetanse i dei medisinske fagmiljøa er nødvendig for at stråleterapien skal få den rette plassen i behandlinga av kreft.
Vidar Jetne

vidar.jetne@radiumhospitalet.no

Fagområde medisinsk fysikk

Stein Kvaløy

Fagområde onkologi

Sigbjørn Smeland

Kreftklinikken

Radiumhospitalet

Oslo universitetssykehus, Rikshospitalet

Montebello

0310 Oslo

Tom Børge Johannesen

Kreftregisteret

Kjell Magne Tveit

Kreftsenteret

Oslo universitetssykehus, Ullevål

Storstilt utbygging av stråleterapikapasiteten var eit av dei viktigaste tiltaka i Nasjonal kreftplan frå 1997 (1). I midten av 1990-åra var berre $60 \%$ av dei medisinske behova for strålebehandling dekte i Helse Sør-Øst (2). Her vart utbygginga fullført i 2006.

Det ligg føre ei rekkje nasjonale og internasjonale utgreiingar der ulike mål på stråleterapibehov kjem fram:

- om lag $30 \%$ av pasientane treng strålebehandling som del av initialbehandlinga (3)

- halvparten av pasientane vil ha nytte av strålebehandling i løpet av sjukdomsperioden (4)

- somme pasientar har behov for fleire strålebehandlingsseriar i løpet av sjukdomsperioden, og talet på behandlingsseriar bør årleg liggje på 50-60\% av kreftinsidensen - i Nasjonal kreftplan talfesta til $54 \%(2,5,6)$

I denne studien vil medisinske behov for strålebehandling vere relatert til talfestinga $i$ kreftplanen: Dei medisinske behova er dekte når talet på årlege strålebehandlingsseriar er $54 \%$ av kreftinsidensen.

Fagleg har det vore ei svært positiv utvikling innan strålebehandling dei siste tiåra. Nyvinningar innan bildediagnostikk har gitt sikrare grunnlag for avgrensing av dei områda som skal strålebehandlast. Den teknologiske utviklinga innan strålebehandling gjer det mogleg å skåne normalvevet langt betre enn tidlegare. Strålebehandling blir ofte nytta saman med andre behandlingsmodalitetar som kirurgi og cellegift, og systematiske studium har ført til betre beslutningsgrunnlag både for terapival og omfanget av dei voluma som skal bestrålast, størrelsen på dei stråledosane som skal gis, og administrasjon av den totale dosen i tid (korleis dosen skal splittast opp i einskildbehandlingar over ein periode).

Det er no etablert stråleterapieiningar i Stavanger (1998), Kristiansand (2001), Gjøvik (2002), Ålesund (2004) og Bodø (2007), med meir eller mindre sterke bindingar til respektive regionssjukehus med større stråleterapiavdelingar. Behandlingskapasiteten ved regionssjukehusa har også blitt utvida, og Norge har no utstyrskapasitet til å dekkje dei medisinske behova. I Helse Sør-Øst er kapasiteten utvida både ved Ullevål universitetssykehus og Radiumhospitalet i 2006, i tillegg til etableringane i Kristiansand og Gjøvik.

Underforbruket av strålebehandling og dei geografiske skilnadene i bruken er vist tidlegare (2). Formålet med denne studien er å vise korleis stråleterapibruken har endra seg i Helse Sør-Øst med auka behandlingskapasitet i perioden 1985-2007. Kreftregisteret har publisert insidensdata fram t.o.m. 2007 (7), og for femårsperioden 2003-07 blir geografiske skilnader i stråleterapibruken drøfta.

\section{Materiale og metode}

Sidan 1976 har Radiumhospitalet hatt eit stråleterapiregister med informasjon om diagnose og sentrale stråleterapivariablar, bl.a. om behandlingsmålet har vore kurasjon eller palliasjon. Registeret vart seinare ein del av driftssystemet for stråleterapi, og frå 1985 har også demografiske data kome med. I Kristiansand og Gjøvik har det same driftssystemet blitt nytta frå oppstarten av stråleterapiverksemda, medan Ullevål universitetssykehus har hatt andre driftssystem. Fram til 2003 vart det behandla få pasientar frå andre fylke enn Oslo ved Ullevål universitetssykehus, og for denne studien er opp-

\section{Hovudbodskap}

- Norge har gjennom Nasjonal kreftplan fått utstyr til å dekkje stråleterapibehovet

- Det er framleis eit betydeleg underforbruk av stråleterapi

- Det er store fylkesvise variasjonar i bruken i Helse Sør-Øst

- Stråleterapibruken må følgjast opp og jamførast med nasjonale handlingsprogram og internasjonal praksis 
lysningar utan diagnosefordeling tatt med for perioden 1985-2002. Frå 2003 har data frå alle fire stråleterapiavdelingane i noverande Helse Sør-Øst vorte samanstilte. For Hedmark fylke har vi lagt til behandlingsseriar utførde ved St. Olavs hospital. For andre fylke er talet på behandlingar utanfor regionen neglisjerbart (KVIST-gruppa, Statens strålevern, personleg fråsegn). I studien inngår ingen individdata, berre samledata frå driftsdatabasane.

Variabelen behandlingsseriar er nytta $\mathrm{i}$ dette arbeidet. Ein behandlingsserie består av ei gruppe enkeltbehandlingar eller fraksjonar, og er i den aktuelle omgangen ei fullført behandling. Dei fleste pasientane får berre éin behandlingsserie, men somme pasientar vil få nytt stråleterapibehov og får då ein ny behandlingsserie - vanlegast i palliativ samanheng. Tala på behandlingsseriar vil vere additive og uavhengig av periodisering. Datakvaliteten for perioden 2003-07 er god. Pga. skifte i driftssystem for stråleterapien ved Ullevål universitetssykehus og registrering av litt ulike sett av variablar tidlegare, er datagrunnlaget noko dårlegare for perioden 1985-2002. Det blir derfor nytta avrunda tal (på heile tusen) for behandlingsseriar for heile perioden.

Vi har relatert talet på behandlingsseriar til kreftinsidensen - publisert av Kreftregisteret - for den same tidsperioden. Data er også splitta på dei enkelte kreftdiagnosane/-diagnosegruppene og relatert til den fylkesvise insidensen for dei respektive diagnosane/diagnosegruppene (7). For perioden 2003-07 er data om bruken av radikal prostatektomi innhenta frå Kreftregisteret for jamføring med den fylkesvise bruken av kurativ strålebehandling ved prostatakreft.

Studien er godkjend av personvernombudet ved Oslo universitetssykehus, Rikshospitalet.

\section{Resultat}

Totalt omfattar materialet dei om lag 86000 strålebehandlingsseriane som er gitt til kreftpasientar i Helse Sør-Øst i perioden 1.1. 1985-31.12. 2007. I same perioden vart det diagnostisert 274726 krefttilfelle i regionen (7). For femårsperioden 1.1. 2003-31.12. 2007 er dei 27946 behandlingsseriane også diagnosefordelte. I gjennomsnitt har kvar pasient fått 1,3 behandlingsseriar i den siste femårsperioden.

Figur 1 viser stråleterapibruken i perioden 1985-2007 relatert til målsettinga i Nasjonal kreftplan. I tillegg til gjennomsnittsverdien for heile regionen er verdien vist for det fylket som har høgast og det som har lågast bruk for kvart år.

Figur 2 er ei fylkesvis framstilling av stråleterapibruken i Helse Sør-Øst for alle kreftdiagnosane, målt i behandlingsseriar relatert til kreftinsidens for femårsperioden 2003-07 og fordelt mellom kurativ og palliativ intensjon.

Ei av dei hyppige kreftformene er pros- tatakreft. Figur 3 viser forholdet ved denne diagnosen, der stråleterapibruken varierer mykje. For jamføring mellom kurativ strålebehandling og radikal prostatektomi er den fylkesvise fordelinga vist i figur 4 . For brystkreft, som er den diagnosen som krev dei største stråleterapiresursane, varierer den kurative strålebehandlinga mellom fylka frå $60 \%$ til $78 \%$ av insidensen, den palliative mellom $17 \%$ og $29 \%$ av insidensen.

\section{Diskusjon}

I starten av perioden var under halvparten av dei medisinske behova for strålebehandling dekte, berre $30 \%$ av behova i fylket med lågast bruk, og $60 \%$ i fylket med høgast. På denne tida var alle stråleterapiresursane nytta fullt ut. Bruken var avgrensa av kapasitet, men tilbodet var sjølvsagt like tilgjengeleg for alle delar av helseregionen. Kapasitet vart frigjort for austnorske pasientar ved utbyggingane i Tromsø og Trondheim i siste halvdel av 1980-åra. Då Nasjonal kreftplan vart lansert (1997), var om lag $60 \%$ av dei medisinske behova for stråleterapi dekte. Den aukande kreftinsidensen og dei stadig høgare kvalitetskrava til behandlingane førte til endå lågare dekningsgrad $\mathrm{i}$ åra som følgde. Frå 2001 ser vi effekten av satsinga gjennom kreftplanen, med etableringane av stråleterapieiningar i Kristiansand og Gjøvik og utvidingar ved Radiumhospitalet og Ullevål universitetssykehus. I 2007 var $76 \%$ av dei stipulerte behova dekte. Positivt er det også at dei geografiske skilnadene er blitt noko mindre, men framleis er variasjonen uakseptabel - 67-91 \% i 2007. Målsettinga har vore å kome opp til behovsdekning før 2010, men tal for 2008 tyder så langt på at det blir vanskeleg å nå det målet. Berre VestAgder ser no ut til å ha passert $95 \%$ behovsdekning.

Figur 2 viser at talet på behandlingsseriar relatert til kreftinsidensen er 39\% for Helse Sør-Øst samla i perioden 2003-07, med ein fylkesvis variasjon på 33-44 \%. Når behovet er vurdert til $54 \%$, svarar det til at $73 \%$ av behova er dekte i femårsperioden, med ein variasjon mellom fylka på $61-82 \%$. Stråleterapibruken i Oslo, Oppland og Vest-Agder er meir enn $30 \%$ høgare enn i Telemark. Dei tre fylka med høgast forbruk er også dei fylka som lokaliserer stråleterapiavdelingane i regionen. I absolutte tal betyr det at i femårsperioden 2003-07 mangla Helse Sør-Øst 10000 behandlingsseriar for å oppnå behovsdekning. Situasjonen er betra gjennom femårsperioden, men også i det siste året var talet på behandlingsseriar 1900 for lågt. Dekninga var $41 \%$, medan det ønskelege er $54 \%$. Desse tala må bli sett i lys av både prevalens - at det er om lag 100000 som lever etter å ha fătt ein kreftdiagnose - og at det årleg no kjem til 15000 nydiagnostiserte krefttilfelle $\mathrm{i}$ helseregionen vår (7).

Av behandlingsseriane er vel halvparten (54\%) med kurativ intensjon, resten med palliativ. Ved behovsdekning skulle ein ut frå litteraturen forvente at dei to gruppene var nær like store (6). Dette indikerer at underforbruket av strålebehandling er større der målet er palliasjon enn der det er kurasjon. For palliativ behandling er det eit opplagt underforbruk i alle fylke, spesielt som behandling mot skjelett- og hjernemetasta$\operatorname{sar}(6)$.

Ved å sjå alle kreftdiagnosane under eitt (fig 1, fig 2) får vi store talmateriale som gir eit bilete av korleis det onkologiske tilbodet varierer geografisk. Samstundes skyggar det over ulikskapar: Eit fylke som brukar strålebehandling mykje ved ein diagnose, kan liggje blant fylka som brukar strålebehandling minst ved ein annan. Som eit eksempel er figur 3 tatt med for å vise forholdet ved diagnosen prostatakreft, der bruken varierer mykje. Her vart kurativ strålebehandling gitt til $31 \%$ av Oslo-pasientane, men berre til $9 \%$ av pasientane $\mathrm{i}$ det fylket som hadde lågast bruk. Det er Oslo-bruken som er mest i tråd med det vi finn i internasjonal litteratur $(8,9)$. Forskjellige fagmiljø har ulike syn på korleis lokalisert prostatakreft skal behandlast, og geografiske variasjonar i val av behandlingsmodalitet er også vist tidlegare (10). For den aktuelle femårsperioden har vi i figur 4 samanstilt bruken av kurativ strålebehandling og bruken av radikal prostatektomi. I vårt materiale er det ikkje slik at lite bruk av kurativ strålebehandling er samanfallande med meir omfattande bruk av radikal prostatektomi. Det er nærare ein samvariasjon: Der strålebehandling har lite omfang, blir det også utført få prostatektomiar. Det må skuldast ulike syn på bruk av aktiv behandling kontra observasjon. Det har til no mangla nasjonale retningslinjer for diagnostikk og behandling av prostatakreft, og det medverkar til framveksten av ulike behandlingstradisjonar. I talet på prostatektomiar (fig 4) kan det vere med enkelte tilfelle der prostatakreft er tilfeldig påvist ved cystoprostatektomi. For palliativ strålebehandling ved prostatakreft er variasjonen frå $14 \%$ i Vestfold og Aust-Agder til 26\% i Oppland. Her er bestråling av skjelettmetastasar viktigaste indikasjonen. Også den høgaste bruken er i underkant av tilrådd praksis (6).

For andre diagnosar er variasjonen mindre når det gjeld bruk i kurativ hensikt. Men sjølv ved brystkreft der det er klåre retningslinjer for behandling (11), er det ein betydeleg fylkesvis variasjon.

Det vil sjølvsagt vere ein statistisk variasjon i stråleterapibruken, men svært mange variablar måtte gå inn i ei eventuell berekning av konfidensintervall. Det er ikkje gjort i denne studien. Ein veikskap med den delen av materialet vårt som omfattar alle kreftdiagnosane (fig 1, fig 2), er at behandlingsseriar mot basocellulære hudkarsinom er rekna med, jamvel om dei ikkje er tatt med i kreftinsidensen. Desse behandlingsseriane utgjer om lag $3 \%$ av det totale materialet. Talet på behandlingsseriar er så relatert til 


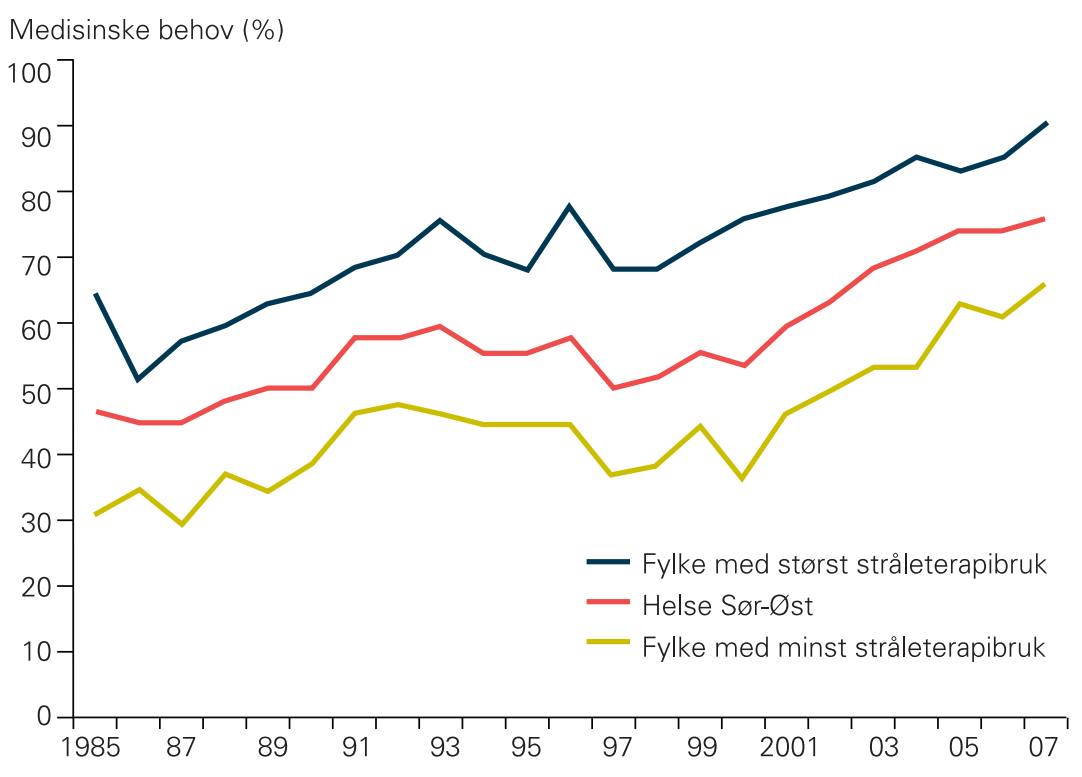

Figur 1 Stråleterapibruken ved alle kreftdiagnosar i noverande Helse Sør-Øst for perioden 1985-2007 relatert til medisinsk behov for stråleterapi Inormert til målsettinga i Nasjonal kreftplan)

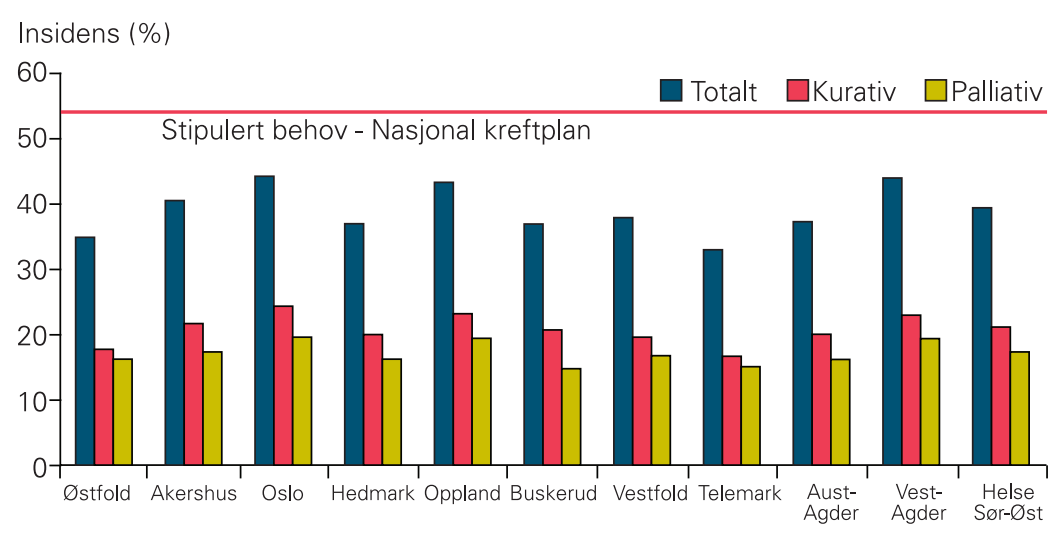

Figur 2 Strålebehandlingsseriar for alle kreftdiagnosar i prosent av insidens for perioden 2003-07 for kvart fylke og for Helse Sør-Øst samla. Behandlingsseriane er delte mellom kurativ og palliativ intensjon

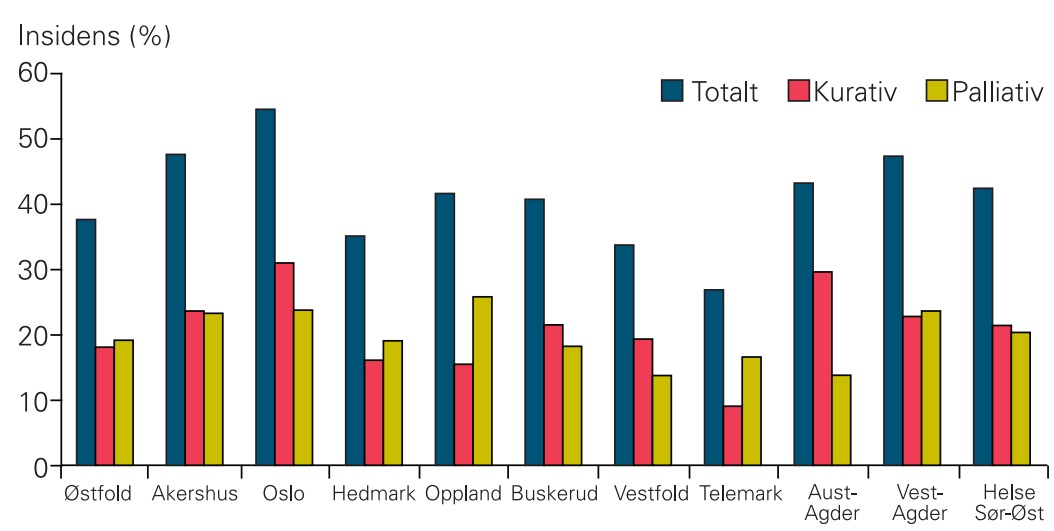

Figur 3 Strålebehandlingsseriar for prostatakreft i prosent av insidens for perioden 2003-07 for kvart fylke og for Helse Sør-Øst samla. Behandlingsseriane er delte mellom kurativ og palliativ intensjon (strålebehandling mot mamiller i samband med hormonterapi er ikkje tatt med) kreftinsidensen i same året, sjølv om behandlingsseriane kan vere spreidde over fleire år etter at diagnosen er stilt, særleg når det gjeld palliasjon. Kreftinsidensen har auka med nær $2 \% \mathrm{i}$ året $\mathrm{i}$ perioden, men det er ikkje gjort studiar av korleis strålebehandlingsseriane er fordelte $\mathrm{i}$ tid etter diagnosetidspunktet. Desse to forholda fører til at både tellar og nemnar i framstillinga av stråleterapibruken for alle diagnosar relatert til kreftinsidens er noko for store, men vi vurderer desse feilkjeldene til å vere utan betydning for å vurdere resultata. Datagrunnlaget for perioden 1985-2002 er noko meir usikkert enn grunnlaget for perioden 2003-07, men også her er uvissa så lita at ho ikkje vil influere på drøftinga av resultatet (fig 1).

Stråleterapibruken i Helse Sør-Øst ligg nær forbruket i dei andre helseregionane. Resultata frå den årlege rapporteringa til Statens strålevern viser ikkje store skilnader i stråleterapibruk mellom regionane, men betydelege skilnader mellom fylka også i dei andre regionane (KVIST-gruppa, Statens strålevern, personleg fråsegn).

Med det vedvarande underforbruket av strålebehandling kan det bli reist tvil om behovsestimata kanskje er for høge. Men samanlikna med internasjonale utgreiingar ligg dei norske behovsestimata heller i det nedre sjiktet. I Sverige låg forbruket i 2001 over dei norske behovsestimata (6). Vi reknar med at ingen fylke har overforbruk av strålebehandling. Dersom alle fylka hadde brukt strålebehandling i same omfanget som Vest-Agder i 2007, ville berre 770 henvisningar mangle i Helse Sør-Øst det året. Dersom det for kvar kreftdiagnose vart brukt like mykje strålebehandling som i det fylket der forbruket var høgast, ville berre 450 henvisningar ha mangla i helseregionen i 2007.

Indikasjonane for strålebehandling ved fleire kreftdiagnosar har nok endra seg i løpet av det siste tiåret, men for somme diagnosar har strålebehandling fått ein større plass, for andre ein mindre. At insidensen av brystkreft og prostatakreft har auka relativt meir enn den totale kreftinsidensen, vil ikkje føre til reduksjon i det estimerte behovet. Brystkreft er ein diagnose der stråleterapibruken er meir omfattande enn for den gjennomsnittlege kreftpasienten, medan prostatakreft ligg om lag på gjennomsnittet i stråleterapibruk. Tidleg diagnostikk vil etter kvart gi seg utslag $i$ eit lågare palliativt stråleterapibehov. For alle diagnosar samla meiner vi framleis at dei behovsestimata som Najonal kreftplan bygde på er adekvate. Det er eit reelt underforbruk av strålebehandling.

Kostnadene knytte til strålebehandling utgjer ein liten del av dei totale kostnadene innanfor kreftomsorga. I Sverige - som ligg framom oss når det gjeld stråleterapibruk er kostnaden for ekstern strålebehandling rekna til 5,6\% av dei totale kostnadene for kreftomsorga (6). Utgiftene direkte knytte til planlegging og gjennomføring av strålebe- 
handling for ein pasient, vil variere frå nokre få tusen kroner og opp til storleiksorden 100000 kroner for dei mest krevande behandlingsopplegga. Til ein kostnad på godt under 10000 kroner kan ei enkeltbehandling gis mot ein smertefull skjelettmetastase og gi pasienten langt betre livskvalitet. I sjukehusverda er dette ein svært låg kostnad. Behandlinga kan også redusere behovet for symptomlindring i sjukehus eller sjukeheim og kan redusere kostnader til medikamentell behandling. På denne bakgrunnen reknar vi ikkje med at økonomiske forhold er ei viktig årsak til underforbruket og dei geografiske skilnadene.

Den manglande stråleterapikapasiteten i regionen heilt fram til dei siste åra førte $i$ periodar både til lange ventetider og til avslag på henvisningar. Det er blitt ein praksis der ein prøver å klare seg utan strålebehandling, spesielt i palliativ samanheng. Når kapasiteten no er på plass, må gammal praksis endrast. Det synest som om det er ein samanheng mellom stråleterapibruk og avstand til stråleterapitilbodet. Men dersom det her berre var reisevegen til behandling som verka inn, burde det ikkje vere nokon grunn til at for eksempel Østfold fylke skulle liggje såpass lågt. Avstanden frå heimen til stråleterapisenteret er vanlegvis ikkje noka stor hindring for at pasientane kan få adekvat strålebehandling.

Langt viktigare enn geografiske avstandar synest kunnskapen i dei medisinske miljøa å vere. At det er store svingingar i stråleterapibruken for ei diagnosegruppe i eit fylke frå eitt år til det neste, finn oftast si forklaring i dei lokale, personalmessige forholda. Der stråleterapisentra er etablerte, blir det lettare etablert ein onkologisk kompetanse utanfor stråleterapisenteret også - $i$ kirurgiske og medisinske avdelingar ved sjukehuset, i lokalsjukehus og i primærhelsetenesta. Regionssjukehusa må ta ansvaret for å få til den same kompetanseoppbygginga i område der det ikkje er stråleterapisenter. For å heve den onkologiske kompetansen vil det vere store behov for ambulante tenester, rådgiving, hospiteringsordningar og vidare- og etterutdanning av legar og anna helsepersonale. Svært viktig er det òg at legar gjennom medisinarutdanninga får meir kunnskap om onkologi og stråleterapi, ved at fagområdet blir etablert som eige fag.

Med kunnskap kjem også henvisningane til strålebehandling. Dersom palliativ strålebehandling kan bli gitt raskt - utan ventetid - vil også terskelen for henvisning bli lågare. Ved skjelettmetastasar kan komplett eller delvis smertelindring forventast hos $80-90 \%$ av pasientane fire veker etter strålebehandling, med betring av livskvalitet og mindre bruk av smertestillande medikament $(12,13)$. Sikring av eit godt smertelindrande behandlingstilbod ved skjelettmetastasar kan vere problemstillingar som må løysast i primærhelsetenesta. Dersom dei finn det naturleg å ta ein telefon inn til stråleterapisen-

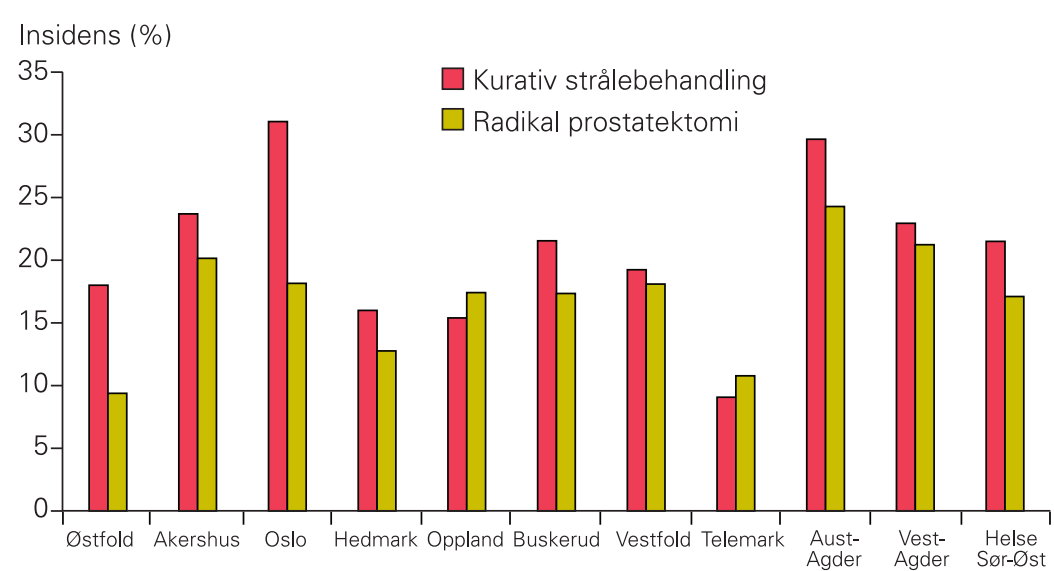

Figur 4 Kurativ behandling av prostatakreft for perioden 2003-07 for kvart fylke og for Helse Sør-Øst samla. Kurative strålebehandlingsseriar og radikale prostatektomiar i prosent av insidensen lenkelte tilfelle der prostatakreft er tilfeldig påvist ved cystoprostatektomi kan vere med i materialet)

teret for å diskutere eit pasienttilfelle, har vi kome langt.

Strålebehandling har vore definert som ein regionssjukehusfunksjon, og då behandlingstilbodet vart etablert ved enkelte andre sjukehus, skulle framleis det stråleterapifaglege ansvaret liggje til regionssjukehusa. Å sikre likeverdig behandling krev samhandling mellom dei mindre einingane og regionssjukehusa når det gjeld pasientlogistikk og bruk av multidisiplinære team.

I den pågåande samordningsprosessen i Helse Sør-Øst er det oppretta regionale fagråd med leiing frå regionssjukehuset, bl.a. eit for kreftområdet. Det er det regionale helseforetaket som har ansvaret for eit godt og likeverdig helsetilbod i regionen (sørgefor-ansvaret, jf. helsereformen). Årlege rapportar om stråleterapibruken i fylka jamførde med nasjonale handlingsprogram og internasjonal praksis, bør inngå som viktig grunnlag når fagrådet skal gi råd til det regionale helseforetaket.

\section{Konklusjon}

Det dokumenterte underforbruket og dei geografiske skilnadene i stråleterapibruken mellom fylka i Helse Sør-Øst kan ikkje aksepterast, korkje for behandlingar med kurativ eller med palliativ målsetting. Situasjonen i denne regionen skil seg lite frå resten av landet. Hovudårsaka til underforbruket og den geografiske variasjonen ligg mest sannsynleg i for lite kunnskapar i dei medisinske miljøa om kva moderne strålebehandling kan yte til pasientane.

Fagmiljøa ved regionssjukehusa og dei andre stråleterapisentra har ei viktig oppgåve i å få bygd opp kunnskap og kompetanse $i$ alle ledd av helsevesenet, slik at strålebehandling får den rette plassen i kreftbehandlinga. Helsebyråkratar og politikarar har her gjort jobben sin, så no er det opp til dei medisinske fagmiljøa å sørge for at behand- lingstilbodet kjem fram til pasientane som treng det.

Oppgitte interessekonflikter: Ingen

Litteratur

1. St.prp. nr. 61 (1997-98). Om Nasjonal kreftplan og plan for utstyrsinvesteringer ved norske sykehus

2. NOU 1997: 20 Omsorg og kunnskap! Norsk kreftplan. Oslo: Helse- og omsorgsdepartementet, 1996.

3. American College of Radiation Oncology. Red book. Guidelines for the ACRO Practice Accreditation Program, 2009 www acro.org

4. WHO meeting of investigators. Optimalization of radiotherapy. Geneva: World health organization. Technical report series 644, 1980.

5. Delaney GP, Jacob S. Featherstone $C$ et al. Radiotherapy in cancer care: estimating optimal utilisation from a review of evidence-based clinical guidelines. Collaboration for Cancer Outcomes Research and Evaluation (CCORE) Sydney: Liverpool Hospital; 2003

6. SBU-rapport 2003 Strålbehandling vid cancer, Nr. 162/1

7. Cancer in Norway. Cancer incidence, mortality, survival and prevalence in Norway. Arlege publikasjonar frå Kreftregisteret, 1985-2007.

8. Foroudi F, Tyldesley S, Barbera L et al. Evidencebased estimate of appropriate radiotherapy utilization rate for prostate cancer. Int.J.Radiation Oncology Biol. Phys., 2003, 55, 51-53

9. Widmark A, Klepp 0, Solberg A et al. Endocrine treatment, with or without radiotherapy, in locally advancet prostate cancer (SPCG-7/SFUO-3): an open randomised phase III trial Lancet, 2009, 373, $301-08$

10. Kvåle R, Skarre E, Tønne A et al. Kurativ behandling av prostatkreft i Noreg i 1998 og 2001. Tidsskr Nor Lægeforen 2006; 126: 912-6

11. Norsk Brystc Cancer Gruppe (NBCG). Blåboka. http://www.nbcg.no/nbcg.blaaboka.html

12. Skjelettmetastaser. Diagnostikk og behandling. Faghefte nr. 7, 2004 Red.: Bruland $\emptyset$ og Skjeldal S. Utgitt av Novartis Norge AS. Id-nr. 1570/06.2004.

13. Falkmer U, Järhult J, Wersäll P and Cavallin-Stähl E. A Systematic Overview of Radiation Therapy Effects in Skeletal Metastases. Acta Oncologica, 2003, 42, 620-633.

Manuskriptet ble mottatt 5.3. 2009 og godkjent 15.10. 2009. Medisinsk redaktør Michael Bretthauer. 